\title{
7 Playing with Fire: Collaborating through Digital Sketching in a Creative Community
}

\author{
Mads Hobye
}

Figure 7.1, a photograph taken at the 2008 Roskilde Festival in Denmark, shows a huge flame exploding from the top of what looks like a cross between the Eiffel Tower and an old oil rig. Two hundred people-some playing big drums made out of water tanks, some cheering, some dancing around the tower-participated in the event. There was a loud uproar right until the explosion. Afterwards, there was silence until the noise returned and another explosion occurred. Each cycle lasted about 15 minutes, and the cycles repeated for five consecutive days. How this project and many others came to be requires us to look at a community experimenting with interactive installations as a way of sketching digitally on a rusty old barge in the South Harbor of Copenhagen. The community is called Illutron, a collaborative studio for interactive art installations.

As a co-founder and a core member of Illutron, I have been part of the day-today discussions and challenges building the community and maintaining it as a fertile environment for creative people. This has enabled me to get an intimate insight into how many small choices have formed the organization and the community around it. In this chapter I will outline some of the properties that, since 2007, have enabled Illutron to work as a collaborative community of people exploring digital materials.

Illutron was formed in 2007 by a group of people with a wide range of backgrounds: artists, designers, performers, programmers, electricians, musicians, and what might be referred to as "electronics wizards." The group started with the intention of creating an open platform for creative and artistic uses of technology. The ideal was that members should have the freedom to be driven by their own curiosity. You didn't have to justify yourself and your work; it was inherent in the culture that somehow, someday, your little experiment would find a greater role in an interactive art installation, in a gallery, or in playful contexts at festivals and events.

The Illutron collective purchased an old 800-square-meter barge to serve as its workspace. It soon became a lab filled with electronic components, steel, and old industrial robots that members had found in scrapyards. The scrap was taken apart, revived, and put into new interactive situations: a discarded score display from the Danish national football stadium became an interactive light wall, and an old diving pressure 


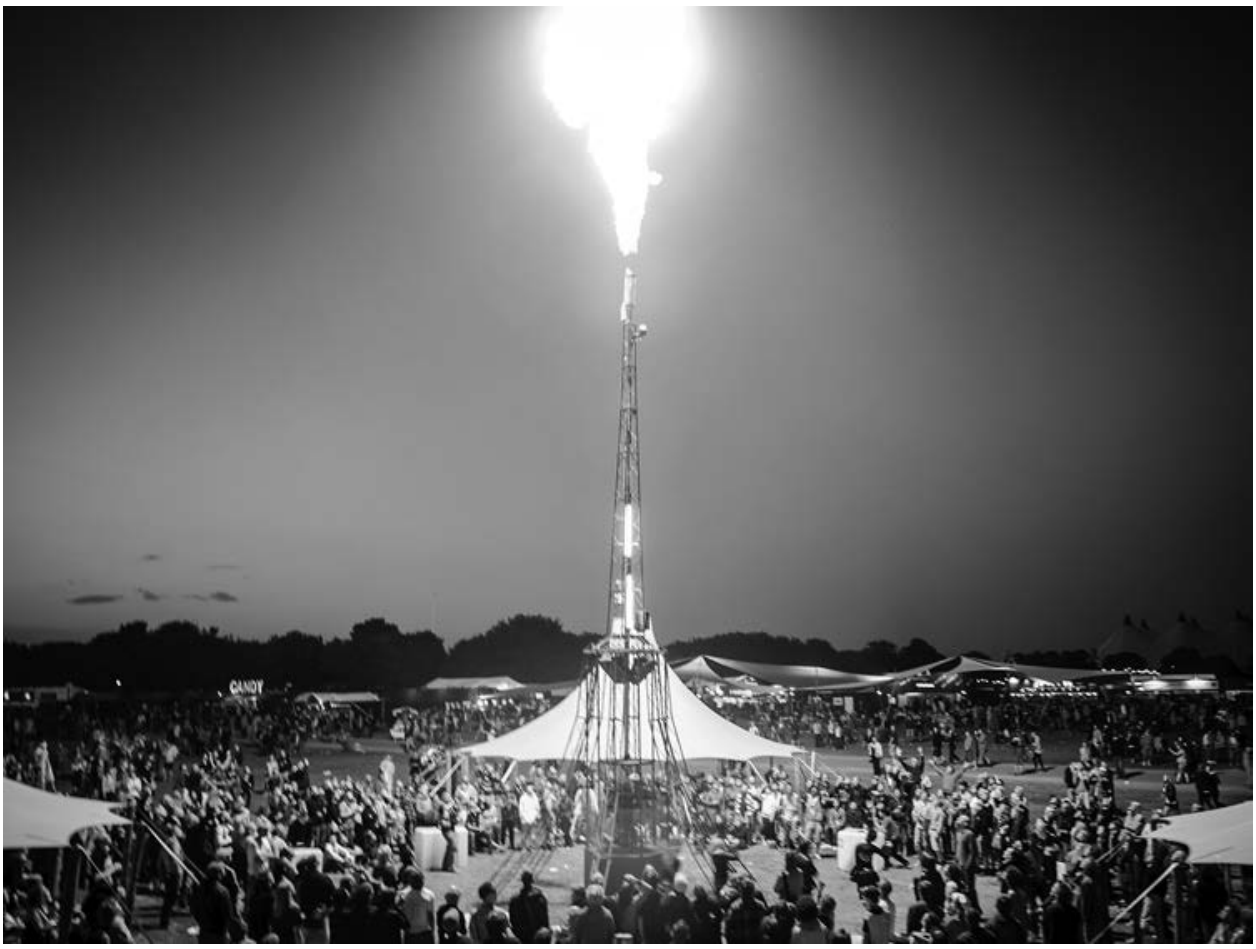

Figure 7.1

Explosion Village. Schack Lindeman (CC:BY-NC).

tank became the buffer tank for an interactive fire cannon. All the experiments were explored by imagining and testing the possibilities they might have in a context of playful participants in the field.

After many installations, it has become apparent that the materials people bring to the space serve as starting points for collaborations forming the art installations, and forming the collective in itself. In this chapter, descriptions of how Illutron came to be and of the design process of three interactive art installations will serve as a basis for understanding some of the intertwined social, technical, and artistic processes that emerge in-and maintain-the community.

David Gauntlett (2011) argues for the potential of considering the creative process of making as a way to create communities that will unlock new innovative capacities. Later in this chapter, I will reflect on how Gauntlett's perspective can help us to understand the community of Illutron, on how the concrete examples can extend Gauntlett's theories with understandings of sketching in digital material, on the importance of frontrunners, on the need for a physical space, and on the qualities of a shared identity. 


\section{The case of Illutron: Finding an organizational form}

To understand how Illutron has become a collaborative platform for a diverse group of people, I first need to introduce how the barge and the organizational values were formed. Furthermore, I need to elaborate on the role of digital material exploration as a facilitator for creative projects with as many as eighty stakeholders involved. This serves as the basis for relating to Gauntlett's model.

Illutron was formed by a group of people who had organized or participated in an annual event called Half Machine, a two-week event focusing on artistic experimentation between humans and technology using multiple expressive forms such as music, dance, robotic, and interactive installations. The event was inspired by Burning Man, a large annual event in Nevada that experimented with the freedom of self-expression by using recycled materials to create art pieces, art cars, and steampunk clothes.

The co-organizers of and participants in the Half Machine events talked about the potential of having a place to do the same thing all year round. We looked at multiple workshop spaces near Copenhagen, primarily closed factories. At the time, however, the economy was on an upturn and either the rental prices were unrealistically high

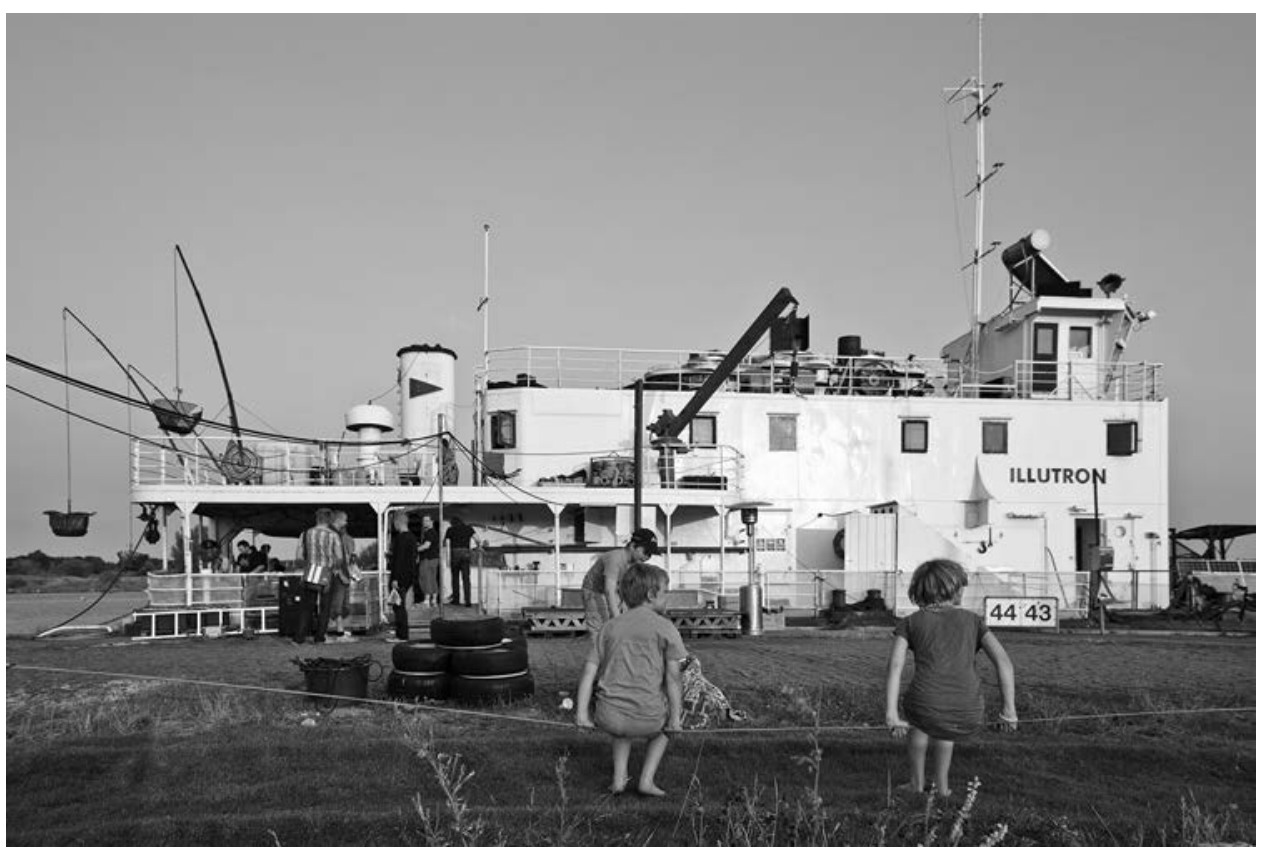

Figure 7.2

Illutron's barge. Mathias Vejerslev (CC:BY-NC). 
or the owners would only give us a short-term lease because they were more interested in selling the property for urban renewal projects than leasing it out to us. One day, a person in the dispersed group noticed a rusty barge lying in a ferry dock. Five years earlier, the barge had been used to build the Great Belt Bridge; it hadn't been used since. It was in horrible shape, but the size and the price were right. Contrary to all odds he managed to get most important parts of the formalities organized. Specifically he managed to convince the bank to lend the money and a free mooring was granted by the Copenhagen harbor. This motivated others to go further with the project and form the studio. It became a standing joke that you had to move out onto the water to do something that was not driven by the market economy; not market-driven in the sense of not focusing on profit, but instead ones own creative curiosity with digital technology.

In the first year of its existence, the barge was called Half Machine, but it soon became clear that the idea of Half Machine was tied so closely to the yearly events that it was necessary to change the name. This enabled the newborn project to form its own principles and enabled new members to influence its direction. We created a manifesto to verbalize some of the motivations behind the organization:

Illutron is a space for adventures and experiments. Artistic and technological frontiers are challenged. Experiments can be based on intuition instead of reason. Creative thinking emerges from below, as long as a fertile creative environment is fostered, where small seeds can find nourishment and grow roots and flower.

Technological progress happens in dialog with the surrounding society and refers to both the past and the future. Our art is a joint creative process in a group, a dialog between the group members and with cultural undercurrents in society. Art involves the audience, they become actors in dialog with the work of art, with its story. We make the works of art and source code available under Creative Commons. We encourage others to expand on our work. (Hobye and Padfield 2009)

The main motivation behind the manifesto was to emphasize the importance of having a space where people could tinker collaboratively. We further acknowledged that we would get inspiration from society and that we hoped to give back to society by encouraging people to build upon our works and by releasing the concepts of the installations and the source codes under Creative Commons licenses.

Apart from the legal arrangements necessary to run a non-profit organization, we didn't make any formal rules. Instead, we looked for pragmatic ways of creating a collaborative culture for the barge. The primary decision-making body was an open meeting every Sunday. We gradually found a good compromise between talking and doing, and we respected the idea that a person who took initiative on a new interactive installation should have a major say in the actual aesthetical design choices of it. Officially, decisions are made by majority, but we have yet to take a vote on anything.

Illutron's biggest challenge was to motivate people to dare to change things and make decisions on behalf of the community. "The ones who take action decide" became a recurring saying in the community, both when people were wondering if they were 
allowed to make a drastic change on the barge and when newcomers wanted to understand what they were allowed to do. After a while, multiple small sayings appeared and it became obvious that they could be harvested and turned into an explicit set of values. This led to ten values that framed our previously tacit culture of collaboration. Here are four of them, as set forth by Hobye, Jensen, and Padfield (2011):

\section{Support initiative}

We strive towards an informal structure. Don't confuse this with non-leadership. The structure reveals itself through who takes responsibility, and who takes initiative. Make sure to look for the good intentions in people's initiatives and find ways to support or improve their process.

\section{The person who acts upon something decides on it}

We don't have time to decide everything together so if you take action and do something you also have the freedom and responsibility to decide on how it should be done. Responsibility in the sense that you should be aware of the common good of the community at the barge. Furthermore it is your responsibility to communicate your plans and actions to the rest of the community.

\section{Sunday meeting is your chance to affect direction}

Sunday meeting should be kept short and effective. Here bigger decisions can be heard in plenum and everyone who is a member has a vote. Decisions on the Sunday meeting should be treated with the uttermost respect.

\section{Embrace newcomers}

Every newcomer should feel welcome and feel that they can participate at some level. No old grumpy men-who know better and already tried it. So smile. This gives your brain endorphins, and makes for nicer pictures.

The values were a symbol of daring to lose control and letting people with initiative take the lead and decide what to do with the space. We e-mailed the values to everyone on the mailing list and presented it at one of the Sunday meetings, but the true communication was done by printing them and posting them on the inside of the rest-room door for people to read. We took the fact that visitors began to take better care of the space as evidence that people had read the values. This enabled people with diverse interests and skills to find the context in which they could participate. The barge became a place for 15-20 core members and about 1,100 people in an extended network.

As part of the organizational structure, we made a rule that every project that came into being because of Illutron should pay at least 10 percent of the revenue as a contribution to the barge. This, combined with a monthly membership fee from the core members, became the primary source of income for the barge. The monthly membership fee varied between 75 and 850 Danish Krone, depending on the member's economic resources and on his or her need to use the barge as a primary workspace. 


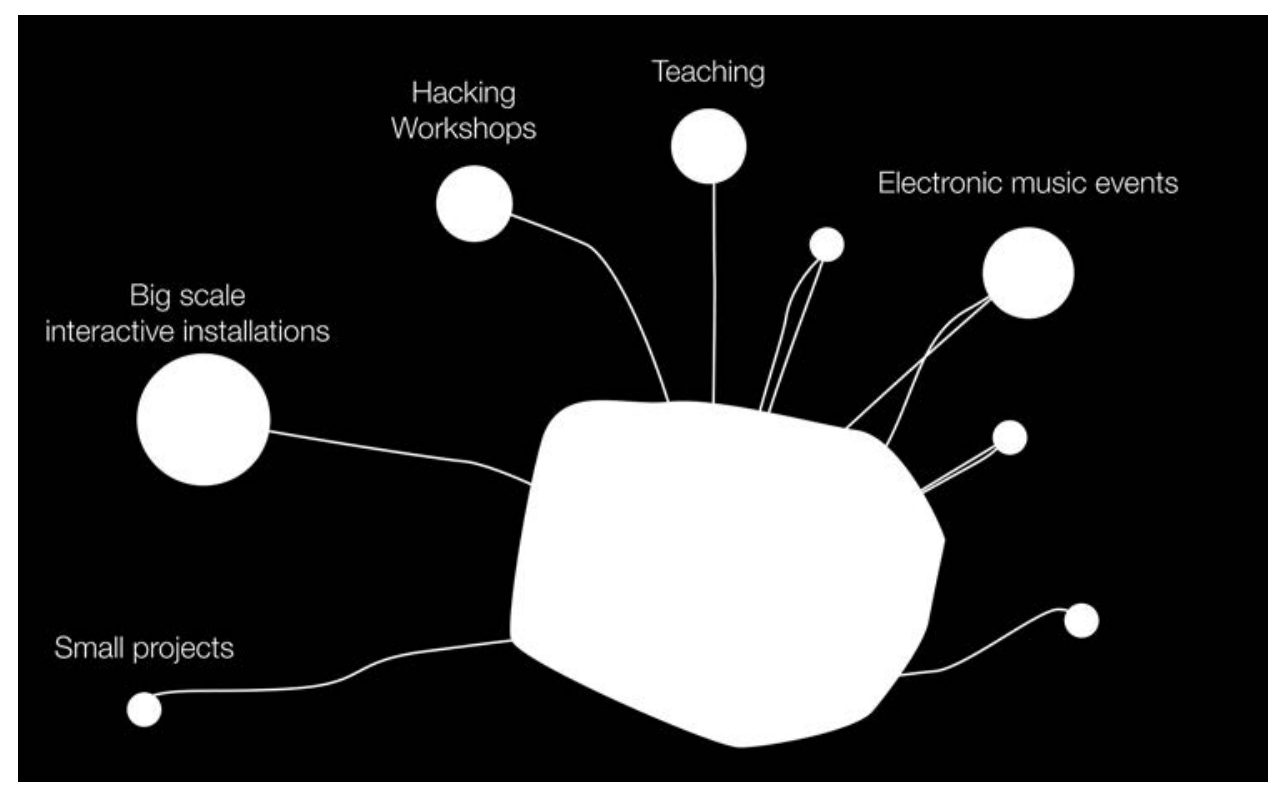

Figure 7.3

A hackerspace-like environment, but with an external mindset of creating for the broader public.

Also important when describing the intrinsic goals of the barge is what might be called "the external mindset." In contrast to a hackerspace, much of the work didn't happen for the sake of the technology itself but was embedded in a mindset oriented toward creating for and with participants in public events, such as festivals and exhibitions.

Although much emphasis has been put on Illutron's organizational structure, the true facilitator of collaboration was in the exploration of digital material. This became obvious after a couple of large projects that showed a direct correlation between how interesting a project was and how many people participated. People were willing to spend their holidays and spare time to get their hands dirty with rusty metal for the sake of creating an interactive art community.

\section{Digital material exploration}

There is no doubt that the organizational choices made have formed the community, but in hindsight the projects undertaken have played a major role in constituting the organizational framework. The projects became the conversation pieces that made it interesting to participate, and they enabled open-ended explorations with technologies. 
In winter, when the water around the barge was frozen and we didn't have any concrete projects booked, only a few people would find time to visit and maintain the barge. As soon as spring came, more people began to work on projects. And after we started work on a larger project, such as an interactive installation, we soon had as many as 50 people working together. Since 2007, this has been the recurring rhythm of the barge. What factors are at work in this rhythm?

In the context of the barge, the term digital material is understood as a combination of electronic scrap material and embedded microcontroller platforms such as Arduino. The electronic scrap material could be old diode displays that once were used to show the score at a soccer stadium. The exploration in relationship to digital material is understood as the process of hacking (as in repurposing old technology for new things) and modifying those components into novel interactive designs. The original aesthetics of the recycled materials are used as inspiration for new forms of expressions. The embedded microcontroller platforms serve to extend the interactions of the scrap materials beyond their original possibilities - for example, to extend the diode displays with motion-detecting sensors that enable them to sense the presence of people in the surroundings and act accordingly. In this digital material exploration also lies a process

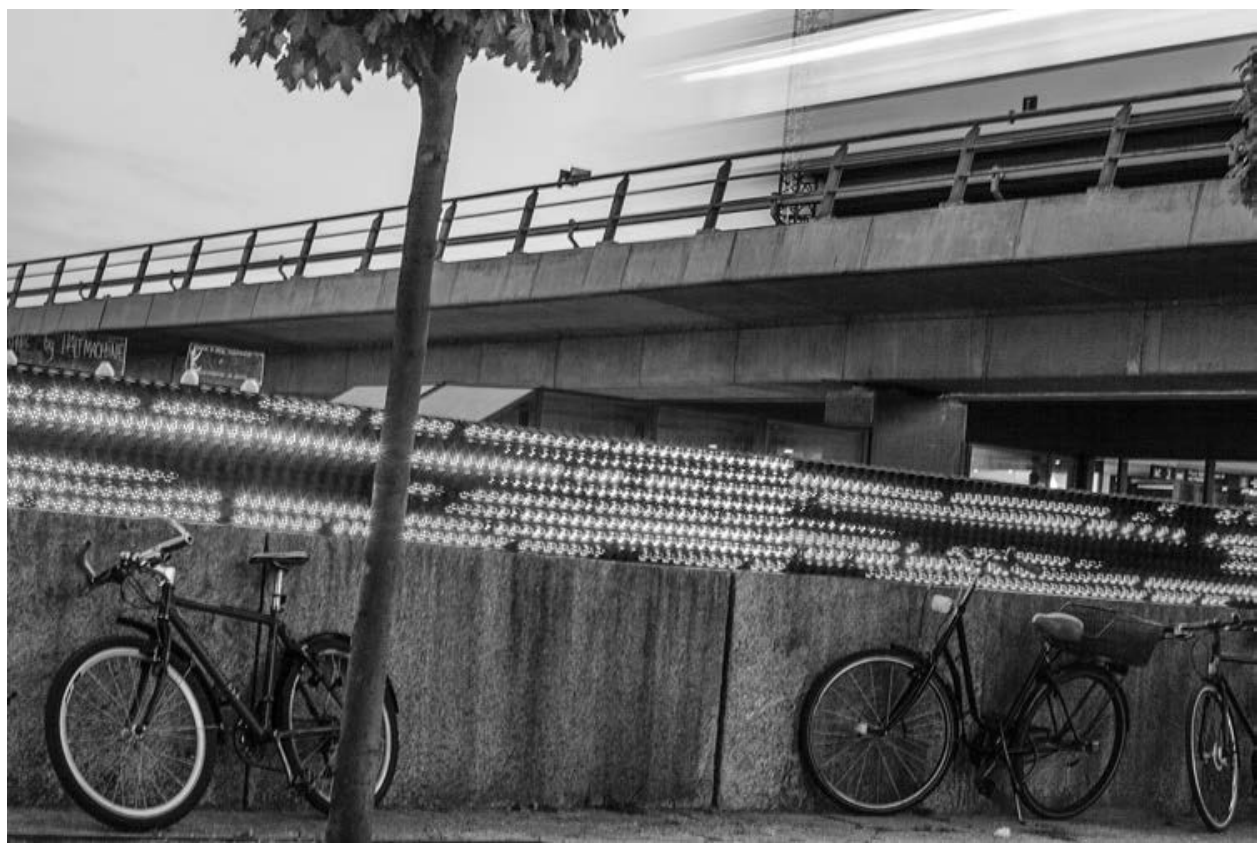

Figure 7.4

Diode displays set up in Copenhagen metro. Mathias Vejerslev (CC:BY-NC). 
of moving the materials into new contexts, hence enabling new interpretations of their roles in the spaces-for example, using diode displays from a soccer stadium in an interactive piece in an art museum. It is a material exploration giving equal weight to both the digital and the physical properties of the material. In this sense it aligns itself to what Vallgårda and Sokoler (2010) call "composite materials" — that is, materials that have both digital and physical properties.

We found the old score displays from the national soccer stadium in 25 big old rusty boxes at the local scrapyard. At first they were unusable, but that rapidly changed when Illutron members began to figure out how they worked. Quite a few of the pixels didn't work at all, and those that did work could show only red, green, or yellow.

For the members, the score displays possessed potential for interactive installations with a certain "retro" aesthetic. Since the birth of Illutron in 2007, the diode displays, which together weigh more than a thousand kilograms, have been used in several installations-one at the Charlottenborg Museum of Art (in an interactive installation at the annual spring exhibition), one at the Roskilde Festival (in an interactive light

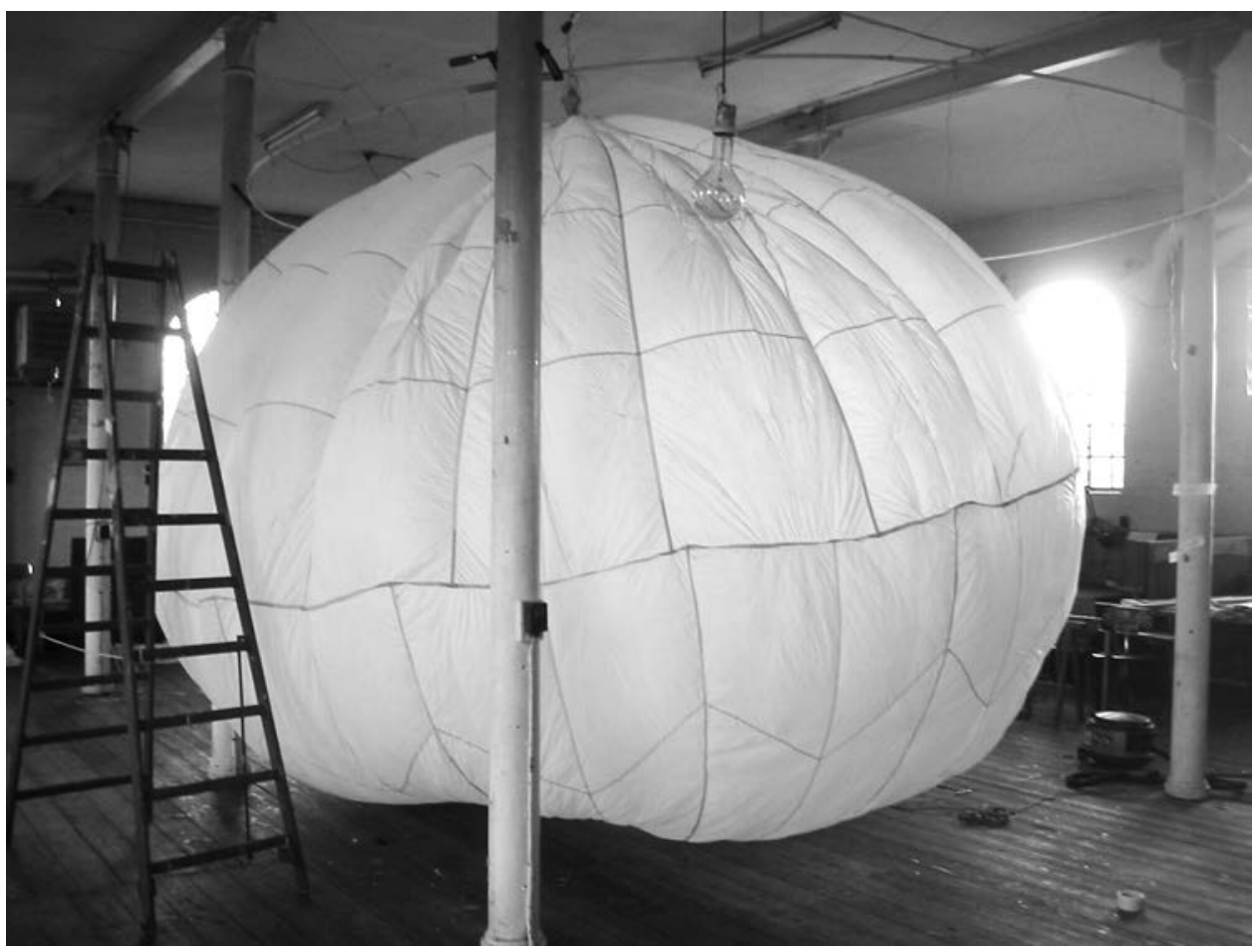

Figure 7.5

Medusae Nilfisk. Nicolas Padfield (CC:BY-NC). 
tower five meters tall), one on the barge (as a VJ wall for parties), several on water (in moving light installations), and one at a Copenhagen Metro station (to visualize the trains going by).

We have lost count of how many people have worked with the displays, and in how many ways. Without the diode displays as a conversation starter, these projects and situations would not have happened. This is not a unique pattern but a recurring theme. Other artifacts, including industrial robots, gas cannons, and DMX controlled theater lighting could also be mentioned. The small experiments served as inspiration for bigger projects, as visualized in figure 7.5. In every case, the conversation began with messy explorations by a few people of how technology might be used in novel ways. In the subsections that follow, I will describe three projects that exemplify how digital material exploration is a source for collaboration and how each project inspires the next.

\section{First story: From small light clouds to Medusae Nilfisk}

The Floating Clouds installation at one of the early Half Machine events, in 2005, was an experiment in the aesthetic qualities of lights shining through fabric. Three balloons of white kite fabric were inflated by small computer cooling fans and would change color by means of three light bulbs inside (red, green, and blue). The balloons were quite passive.

Two years later, Roskilde Festival (a music festival with 100,000 participants) asked if we would be interested in making an installation for a usually badly lit area that many people walked through. It was basically a boring passage between two major stages.

We brainstormed about possible ideas, and "floating clouds" similar to those in the 2005 installation but much larger came to mind. Two old military parachutes were sewn together to form a sphere. Lights were added inside, and the sphere was inflated with antique Nilfisk vacuum cleaners (in reverse mode). Some members had begun to experiment with ways of igniting gas to create large interactive flame effects, and we thought of combining the two projects into one installation. Gas flames would be mounted on top to create fire explosions in the night. The Medusae Nilfisk project was born.

What in theory seemed to be a straightforward task quickly proved to be a constant battle with the materials. Each parachute had to be dipped in glue five times to make it sufficiently airtight. We had to find a way to control the fire cannon. We had to find a way to place the installation high enough that participants would not be able to destroy it. And participants had to be able to affect the light and set off the fire.

Seeing the installation with the lights, the fire, and the parachutes for the first time, we were pleased with the result and surprised by properties that we had not anticipated. The glue gave the parachutes a translucent texture. The metal frames that held the lights cast shadows on the parachutes, making them resemble super-sized Chinese lamps. 


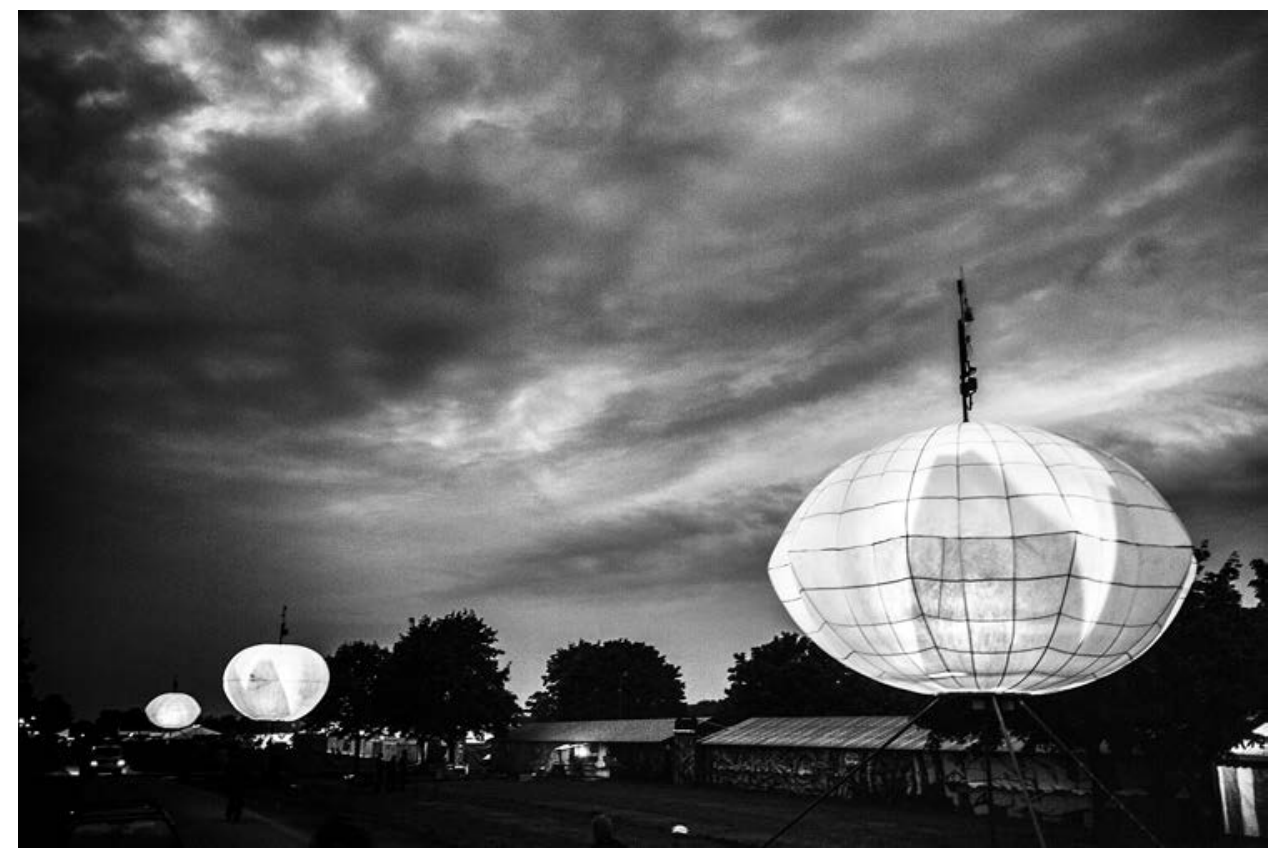

Figure 7.6

Night view of the Medusae Nilfisk installation. Schack Lindeman (CC:BY-NC).

For interactivity, we provided two poles that, when touched simultaneously, would set off the fire and change the colors of the lamps. We placed the poles so far apart that at least three people had to hold hands to connect them. At first, none of the participants seemed to understand what they were supposed to do with the poles. After an evening of explaining to random people that they would be able to set off the fire by holding hands, people started to explore it on their own. On the second day, the rumor had spread, and we observed an ongoing dialogue in which people would run around asking other people to hold their hands so they could see the fire. What we at first thought of as a failure in interaction proved to be a simple way of engaging people in playful interactions (Hobye, Padfield, and Löwgren 2013).

At first the Medusae Nilfisk project was mostly the work of four people, but slowly more and more people joined the project and helped out in various ways. We didn't plan this; it was a consequence of our needing help with various things. For example, we asked an engineer to help us get the touch-sensing poles to work. We had made a touch-sensing system that worked perfectly in the dry conditions of our workspace, but when we implemented it in the wet mud of the festival we could not read a signal. It seemed the signal went straight down into the ground instead of back into our 
measuring probe. With duct tape, hot glue, and components from a discarded circuit board, the engineer was able to get the system to detect if people had connected the two poles. It was like magic to us, and we all wanted to understand how he did it. Although he was not originally a member in the project, he ended up staying for a whole week, fixing things and playing with electronics.

\section{Second story: From drum experiments to Explosion Village}

In the fall of 2008, inspired by the playful interactions we had observed at Roskilde Festival, we began to experiment with percussive interfaces. We wondered how we could make an installation that allowed multiple festival participants to play music together. Answering this question would be a way of utilizing the energies of multiple participants interacting with an installation in real time.

In the first experiments, we used wooden boxes wired up with contact microphones. The sound from the wooden boxes was filtered through various sound effects to create interesting sound dynamics. The sound was analyzed and converted into light, so you could see your own drumming and a visualization of the overall activity (energy) in the installation. The experiment was rough-a bunch of people jumping on the boxes and drumming randomly. At certain times we sensed qualities that seemed likely to get a lot of people to create rhythms together. The project became quite enchanting, and we wanted to see what would happen if it was scaled up.

The next year, Roskilde Festival asked if we wanted to do an installation in an area larger than the one we had been given the year before. We proposed the interactive drumming installation combined with a huge gas cannon (The member of our group who had made the fire cannon for the Medusae Nilfisk installation said he would go to the festival again only if he could make the biggest fire cannon possible). Eventually we came up with the idea of the Explosion Village with multiple drum interfaces. When the participants had drummed for a certain time, a huge gas cannon in the middle of the site would fire.

Explosion Village was a much larger project than Medusae Nilfisk. Six groups worked on various parts of the installation. The musicians and the sound engineers explored different physical materials that would create interesting sounds when drummed on. The electricians and programmers built control systems that connected the drum interfaces to light effects and measured the activity so the explosion would go off at the right time. The people working with the gas cannon investigated ways of releasing a lot of gas while maintaining a safe and controlled situation. The groups were formed around key people within the community who took the lead on solving a specific problem within the larger project. There was a lot of interaction between members of different groups, especially when interesting experiments were underway. When the gas cannon was about to be fired for the first time, everyone worked on the preparations. 


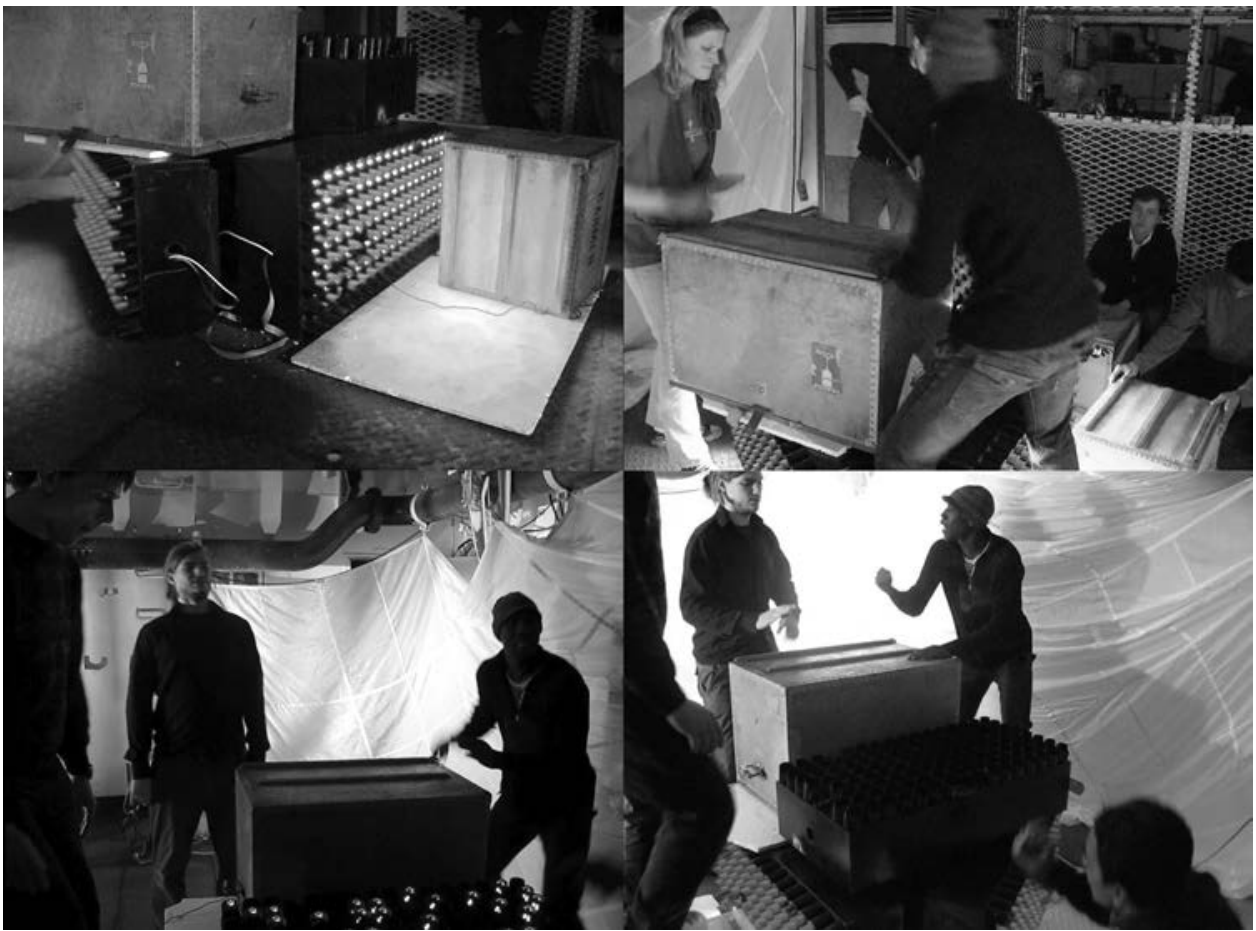

Figure 7.7

The initial experiment with drum interfaces. Mads Hobye (CC:BY-NC).

Besides people with assigned responsibilities, more and more people began to hang out and help. We had to ask the festival for tickets for sixty volunteers.

One of the most active individuals became the project's leader. This was never officially decided, but everyone knew that he was the one who could give status updates and could make sure that your part would fit into the whole picture, both technically and physically. His primary role was to think of all the things that had been overlooked-for example, making sure that we had containers for our gear at the festival and that there were people cooking so that we wouldn't starve while building the installation at the otherwise empty festival site.

Thousands of participants constantly played with the Explosion Village installation throughout the festival, drumming energetically while singing and dancing around the fire tower. Its success was dependent on people working behind the scenes, fixing broken lights and experimenting with different interaction patterns while people were playing. Musicians explored the possibilities of making people play together by playing along with them on various instruments, including electronic drum machines and 
a wooden double bass. It was an intense experience trying to play with the designed framework while 200 people were drumming like mad on big glowing water tanks. Through the code and the audio processing interfaces, we became co-players with rhythms created by the participants.

When the festival was over, we all were dirty and tired. We went home to get a week of rest. When we returned to the barge, the Illutron group had grown, mostly in its extended network, but we also had a few more core members.

\section{Third story: From touch experiments to Pyrolandia}

In 2010, we were asked to do an installation in the city of Roskilde at midwinter. Inspired by the experiment with the touch poles, we had discussed and experimented with ways of digitally sensing full-body touch-sensing. We now wanted to inspire an interaction that had more rich interaction properties than just a simple stimulus response of a gas cannon firing.

We wanted to make a more advanced fire cannon, partly because the rapid expansion of propane gas tends to freeze pipes, especially in the cold winter, and partly because we wanted to be able to control the size of the flame. We decided to use diesel this time.

The quest for understanding full-body touch-sensing led to multiple small experiments with circuit boards and programs designed to interpret when two bodies touched. We found that we were able to detect when one of three dancers got a hug from a participant by reading the capacitance of the individual dancer. When one dancer was connected to another body (a participant), the capacitance would change. For this to work each of the dancers had to wear a wire that was connected to the main circuitry. This became our first full-body touch-sensing installation. In Pyrolandia, the touchsensing installation was incorporated in an aural and visual performance in which the amount of bodily connection (i.e., the change in capacitance) with the audience correlated to the amount of fire from the fire tower.

\section{Connecting through digital sketching}

Gauntlett's (2011) model of "making is connecting" sheds new light on processes such as the one that shaped Illutron and how digital material exploration became a central aspect of the community. On the other hand, experiences on the barge highlight some of the concrete nuances that Gauntlett seems to miss, thus enabling us to develop his theory further.

Gauntlett challenges the idea of creative processes as something that should be judged on their outcomes. He leaves behind, much in line with Dewey (2005), the institutionalized traditions of evaluating art as an end product and points out the inherent pleasure of the making in itself. The making, thus, becomes a creative process 


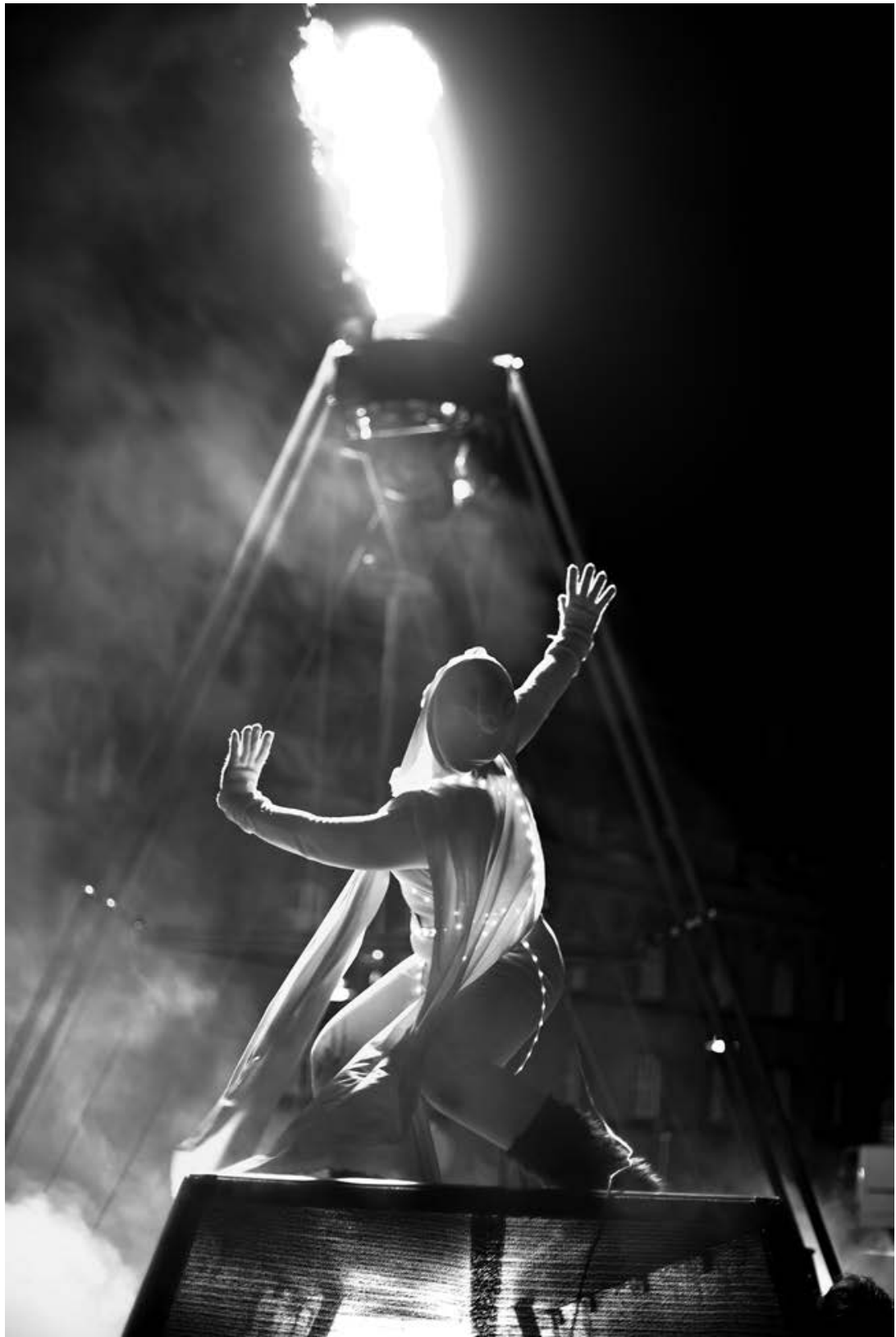

Figure 7.8

The Pyrolandia installation, with a touch-reactive performer dancing in front of the flame effects. Mathias Vejerslev (CC:BY-NC). 
where the pleasure is first and foremost found in doing and building for your own satisfaction. To him, activities like small improvements to your home have satisfactory qualities in themselves.

Through making, people become participants rather than merely spectators or consumers. Further, you want to be recognized for what you do, not by being the first in the world to make something, but by sharing your skills and work in a community of interesting and interested peers. By sharing and making a mark, you become alive, connected and find a shared purpose, which Gauntlett (2011) argues is essential for human stability, happiness, and well-being. Hence, self-realization will not work if pursued in solitude. The source of happiness lies in everyday life collaboration as part of a community.

Gauntlett's arguments align well with the story of Illutron and how making has become a central aspect of its ecosystem. First and foremost, the barge was intended to be a space where people could create on their own terms and for the joy of creating itself. Second, the three stories recounted above exemplify how digital material exploration became a central aspect of sharing and collaborating within a dynamic group of people.

Gauntlett (2011) notes that sharing is a way of making in collaboration. He mentions the open-source software community and people sharing knitting patterns as examples of people building upon the work of others. In the case of Illutron, the digital material exploration has an inherently fluid structure. Parts and ideas from previous projects are reused and modified in new projects in a never-ending process. Projects are always open to new interpretations. This has been formulated in the manifesto by encouraging others to build upon our work, but also to consider the works as invitations for participants to use on their own terms in a collaboration with us.

In the case of Illutron, the digital material exploration can be considered as a form of sketching. By considering every project a sketch that hasn't found its final form, we make room for exploration and modification. Buxton (2007) introduces the concept of sketching user-experience as a way of enacting different interaction scenarios through easily moldable materials such as foam blocks and cardboard mockups. This enables the designer to quickly produce new sketches without the time-consuming work of programming and soldering functional prototypes, hence enabling the designer to have a short iteration cycle between ideas. Consider how collaboration unfolds through sketching in the context of Illutron.

At Illutron, people usually tinker with rapid prototyping tools that are technically more advanced than cardboard mockups, including embedded platforms (such as Arduino and Wiring) and creative programming languages (such as Processing, openFrameworks, and MaxMSP) that can be used to quickly prototype different interaction scenarios. 
Illutron's sketching approach aligns with the concept of "sketching in 4D" (Kyffin et al. 2005) which underlines the need to move beyond screen-based interaction into a three-dimensional perspective, a spatial approach to sketching that requires a sensitivity to the forming of the materials itself. Kyffin et al. (ibid.) further argue for a fourth dimension: the temporal dimension. They exemplify this through a learning process in which students have to create prototypes via a set of technical steps. The individual steps in the process become a generative way of understanding the expressions of the design ideas and generating new ideas to elaborate on. To embrace evaluation and idea generation as a combined process, Kyffin et al. suggest, much in line with Buxton (2007), that one should start out with prototypes that are as "lo-fi" as is possible. With each iteration, a new layer of complexity is then added. Simply put, the students start out with simple sketches that they turn into mockups that can be acted out manually. In the final stage, they construct a working prototype with, for example, a programmed microcontroller, sensors, and actuators.

The key difference between the approach put forward by Kyffin et al. (2005) and the approach utilized on the barge lies in the sketching starting point and how the sketching evolves over time. Whereas the members of Illutron brainstorm (in a relatively disorganized way) about new projects, the initial sketching is actually done closer to what Kyffin et al. would consider a part of the final phases. To exemplify, the Illutron prototyping might start with a microcontroller (in our case an Arduino board), a first iteration that is considered an initial and crude mockup. This initial mockup serves to communicate an idea or to solve a core feature in the interaction, for example how to detect touch between two bodies or how to make large-scale fire effects in a controlled way.

There are two reasons for the members of Illutron having a more technically advanced starting point than Buxton's argument for lo-fi prototyping and the starting point used by Kyffin et al. First, it is a consequence of the rather high technical skill level present on the barge. It simply doesn't make sense to make a foam mockup and act out the interaction when one can just as easily wire up a servo to an Arduino board and see the actual working prototype from the beginning. This is also a consequence of the evolvement of general usability within microprocessor programming. In 2005, when Kyffin et al. argued for a fourth dimension (the temporal dimension in the form of real-time interactive properties), one had to be able to set up ones own chain of tools for one to be able to program a microcontroller (a task that required quite a bit of technical knowledge). Today, easily programmable microcontrollers, such as Arduino, set new standards in usability for cross-platform out-of-the-box programming interfaces. The second reason for Illutron's more technically advanced starting point is a consequence of the fact that most of the design within the community is rooted in technical challenges. For example, finding a way to detect body presence between two people works simultaneously as a technical challenge and a conceptual idea generator. 
One could say that the Illutron sketching process is the reverse of the one proposed by Kyffin et al.-that Illutron sketching begins with the technical challenges of the sensors and the interaction and uses it as a skeleton around which to build the physical properties of the installation.

Using software development environments and embedded platforms for rapid prototyping in the early phases of design and development differs from using materials such as cardboard and styrofoam to make mockups. I argue that our technical starting point is given by the nature of the technicality of the materials and the engaging experiences we want to create. For example, in the case of the experiments with drumming, it would not have been possible to understand the interaction and the possible aural and visual feedback without experimenting with contact microphones and real-time analysis of the sounds. The interaction aesthetics (Petersen et al. 2004) we seek require an embodied (Dourish 2004) or somaesthetical (Shusterman 2008) exploration right from the early phases of the experimentation, something that cardboard mockups cannot facilitate. One can assess the potentials of the experience only by interacting with the working prototypes.

Thus, the sketching process at Illutron can be understood as a digital extension of Buxton's (2007) sketching user-experience and can be seen as a reversed version of the 4D sketching approach of Kyffin et al. (2005); all three of those approaches have similar agendas of gaining a craftsman-like way of exploring the digital materials. As a consequence of Illutron's digital/technical starting point, I argue that it should be considered digital sketching - a technique that resembles traditional sketching techniques, but with a focus on sketching in digital material (Hobye 2014). How this unfolds in the collaborative environment of Illutron depends on the factors described below.

\section{In the lab vs. in the field}

At Illutron, the immediate environment around the barge where the initial experiments are done can be considered the $l a b$, and the larger context in which the installations are deployed can be considered the field. This is in line with the definition, proposed by Koskinen et al. (2011), according to which the lab is a decontextualized free space into which people bring things of interest for experimental studies, and where the field is a contextualized place where one studies how the designs are used, made sense of, and how they are talked about by audiences who become participants. Because Koskinen et al. study discrete cases, they do not elaborate on the transformation of the experiment when going from the lab to the field. In the three stories about Illutron projects recounted above, there is a natural inherent interplay between the lab and the field.

In the setting of the decontextualized lab of Illutron, exploration relies on enactment and the prediction of interaction, i.e., imagining how "real" participants will 
use it. Here, we do what Schön (1987) would call "knowing-in-action." Our tacit understandings of what works become the primary ground for choosing the way forward, understanding how participants have interacted in other projects, and reassessing how this relates to the current ideas. This is, as was mentioned above, a "messy" and open-ended process. Multiple experiments pull in different directions, and those experiments are mostly driven by questions such as "What if we can sense the distance between humans?" and "What is the perfect mixture between gas and air?" This results in workspaces filled with half-finished experiments. It becomes what Schön would call "reflection-in-action," a reflective process in which ideas materialize through collaborative kneading. The ideas and experiments become traveling conversations in which personal ownership is lost and it is often difficult to remember who came up with an idea first.

The decisions made through experiments and through enactments of interaction scenarios become our sketches to try out in the field. Although the experience of the crew enables us to predict some of the possible interaction scenarios, we still need to modify it to scenarios we had not anticipated. This becomes a running-in period during which parameters are tweaked to accommodate the actual interaction. Hence, the sketches serve as rudimentary frames to modulate live while participants interact with the installations in the field.

The field is an ongoing conversation with the participants through their interactions with the installations. Thus, it becomes a lab-in-practice where the initial ideas and designs imagined are bent and modulated to fit the context. There can be a multitude of interests, but a common underlining theme has been to inspire people to play with and explore the installations with one another.

The dialogue between the lab and the field characterized above are central to understand when we elaborate further on the collaborative group dynamics put forward by Gauntlett (2011), because it leads to an involuntary exclusion of members and a need for front-runners for the community to evolve.

\section{Involuntary exclusion and the need for front-runners}

In the examples presented above, multiple people working on a project together became a way of including new members into the core group. Gauntlett (2011) would consider this a process of communities forming through mutual creative interests. However, as much as this became a fruitful way of engaging new members, it also had its limitations. Specifically, the technical mindset of the community tended to lead to involuntary exclusion, and it depended rather heavily on front-runners.

The use of advanced technology and the advanced shaping of materials require that the designer have technical expertise. It has become apparent, through many projects, 
that the person designing an installation and the person building it are almost always the same.

The technical skills required to do digital sketching have led to involuntary exclusion. If you don't know how to work with the materials, you tend to become a visitor at the barge instead of a participant. In our experience, a few people became exceptions to this tendency because they had enough social skills and enough technical knowledge to have conversations about projects without actually building the projects. They found roles as project leaders or activists, helping with necessary but non-technical elements of the projects.

As a general rule of thumb, a person must have a set of (most often technical) skills to get involved in conversations about projects. It has not been uncommon to see members evolve over time and acquire multiple secondary skills by learning through collaboration with others. Now that Illutron has been active for several years, there is a general understanding of the individual members' primary and secondary skills-an understanding that comes in handy when new projects must be coordinated.

Since a larger project requires a period of preparation, negotiation of formal contracts, and conceptual presentation, Illutron is highly dependent on the front-runners to lead the way. The saying "Those who take initiative decide" is good for the frontrunners, but it leaves little room for newcomers and activists who lack technical skills or sufficient knowledge of the working culture of the barge. They tend to be passive until someone with knowledge and greater experience takes the lead.

\section{A shared space and a shared identity}

Gauntlett (2011) mostly focuses on collaborations through unstructured online networks of people. Illutron, by contrast, has a more rigid physical and social structure, in which emergent collaborations occur. The barge is a physical workspace and a community with a shared identity. The physical workspace enables us to have much more hands-on collaboration than can be had in a virtual collaboration. Working on the same physical things together is different from tinkering with the same idea across the world. The latter could be described as a parallel virtual creative process that is useful for sharing and developing smaller projects (such as cooking recipes) and for working on software development. The former could be described as creative collaboration in a shared workspace. Our shared workspace has enabled us to create large-scale installations with as many as 80 people working on elements that are later combined in a greater whole. Furthermore, the physical space has enabled us to carry on traveling conversations about experiments. A small experimental prototype that one person made during the winter may lie on the floor for months until someone picks it up, builds upon it, and turns it into something great the next summer. 
Besides the physical space, the identity of Illutron enables us to have a generous attitude toward ownership and crediting. People are able to share their ideas because they know that even if somebody else ends up using their idea or technology it will still be part of a project that will be branded under the shared identity. This enables us to focus on large-scale collaboration instead of small-scale self-realization.

In the beginning, we had many discussions about what titles and roles might be used when it came to defining people on websites and in projects. However, the shared creative processes made it practically impossible to figure out who should be credited for the ideas and the construction of the individual parts of projects. Two other questions were "What constitutes a work of art?" and "Who is the artist?" This led us to do two things. We decided to give equal credit to all those who were involved in a project, even if only remotely). You can see an example of this in the acknowledgments at the end of this chapter, where people are credited without any mention of their individual roles. In the manifesto, this is put as follows: "Credit all involved (including the tea person)." We also decided to consider everyone an artist:

\section{Everyone is an artist hence nobody is an artist}

Everybody pulls together to make art and everyone contributes to the art. Therefore the role of being "the" artist is non existing. (Hobye, Jensen, and Padfield 2011)

By considering everyone an artist, we leave behind the fine-arts institutions' need for classification and evaluation and instead focus on the qualities of the experiments and on interesting ideas people come up with under the identity of Illutron.

The individual ambitions of the members of Illutron differ from Gauntlett's descriptions of informal online communities. Online sharing communities have ambitions of recognition within their own circles. Compared to Gauntlett's perspective, Illutron also has an external focus. The creation of interactive art projects in public spaces attracts people with artistic or technical ambitions, something that could be an obstacle to free sharing of ideas and concepts within the organization. Through a shared identity, and by crediting everyone involved in projects without specific details on who did what, we defuse some of the inherent fear of sharing openly with other members. That gives a member the freedom to define his or her own contribution when describing the process to others inside or outside the community.

\section{Conclusion}

One of the objectives of this chapter was to add to Gauntlett's (2011) concept that "making is connecting" by describing and analyzing how Illutron works. Gauntlett's way of putting focus on the act of making together as an integrated part of connecting is true when it comes to the relationship between the fragile community on the barge and the digital material exploration that goes on there. Without our conversations 
about digital material we would not have had interesting projects, and without interesting projects we would not have been able to evolve the organization.

The main organizational question is how sustainable this rather informal model will be. Will the ecosystem slowly dry up, or will there always be new potential projects and new curious people? Since 2007, we have seen a slow change in the membership, "new" people learning from "old" people and some people moving on. Ideally, this would mean that in the future most of the founders have been exchanged, while some of the knowledge and experience is maintained and developed in a never-ending process.

\section{Acknowledgments}

Current members of Illutron (as of 2013): Mads Hobye, Vanessa Carpenter, Peter Madsen, Schack Lindemann, Nicolas Padfield, Bent Haugland, Daniel Brooks, Tobias Lukassen, Christian Liljedahl, Harald me. Viuff, Joachim Ante, Mona Jensen, Johan B. Lindegaard, Jonas Jongejan, Mathias Vejerslev, Dzl (Nicolaj Møbius), Simo Ekholm, Eva Kanstrup, Lin Routhe, Troels Just C, Benjamin Weber, Halfdan Hauch Jensen

Floating Clouds: Mads Hobye, Nynne Just Christoffersen, Nicolas Padfield

Medusae Nilfisk: Thomas Jørgensen, Nicolas Padfield, Mads Hobye and Schack Lindemann, Vibeke Hansen, Dzl (Nicolaj Møbius), Harald Viuff, Bo Boye

Score display hacking: Jacob Remin, Peter Boné, Kasper Pangbrun, Troels Christoffersen, Thomas Fabrik, Nicolas Padfield, Mads Hobye, Sonny Windstrup, Johan Bichel Lindegaard

Soundscape: Mads Hobye, Daniel Brynolf, Henrik Svarrer Larsen, Romy Kniewel, Khorsed Alam

Explosion village: Anders Olsen, Andreas Bennetzen, Annechien Seesink, Casper Øbro, Claus Jørgensen, Eva Kanstrup, Frederik Hilmer Jensen, Harald me Viuff, Helle Falk Jakobsen, Jakob Sindballe, Johannes Asker Andersen, Jonas Jongejan, Jun Philip Kamata, Karen Gamborg Knudsen, Kasper Rasmussen, Ki Elvira Roux Fuglsang, Mads Hobye, Marc Cedenius, Mathias Vejerslev, Morten Vendelboe, Nicolaj Møbius, Nicolas Padfield, Peter Madsen, Pia Nielsen, Vibeke Hansen, Rikke Rasmussen, Schack Lindemann, Simon Lausten Østergaard, Sofus Walbom Kring, Sonny Windstrup, Stig Eivind Vatne, Tanja Jørgensen, Thomas Fabian Eder, Thomas 'Fabrik' Jørgensen, Tobi Twang, Vanessa Carpenter, Roskilde Festival Volunteers

Pyrolandia: Christian Liljedahl, Nicolaj Møbius, Nicolas Padfield, Harald Viuff, Tobi Twang, Schack Lindemann, Brian Vandal, Sonny Windstrup, Mads Høbye, Mona Jensen, Rikke Rasmussen, Gemma Peramiquel Borjas, Emma-Cecilia Ajanki, Sophia Mage, Henry Tornow, Vanessa Carpenter, Johan Bichel Lindegaard, Lizette Bryrup, Max 
Kim Tobiasen, Mathias Vejerslev, Lone Juul Dransfeldt Christensen, Christian Wang, Frederik Thaae

Photographers: Mathias Vejerslev, Schack Lindeman, Sonny Windstrup and Mads Hobye

\section{References}

Buxton, Bill. 2007. Sketching User Experiences: Getting the Design Right and the Right Design. Elsevier/ Morgan Kaufmann.

Dewey, John. 2005. Art as Experience. Penguin.

Dourish, Paul. 2004. Where the Action Is: The Foundations of Embodied Interaction. MIT Press.

Gauntlett, David. 2011. Making Is Connecting: The Social Meaning of creativity, from DIY and Knitting to YouTube and Web 2.0. Polity.

Hobye, Mads, Mona Jensen, and Nicolas Padfield. 2011. The Values of Illutron (updated version at http://illutron.dk/values/solo).

Hobye, Mads, and Nicolas Padfield. 2009. Manifesto 1.1 (updated version at http://illutron.dk/ manifesto/solo).

Hobye, Mads. 2014. Designing for Homo explorens: Open Social Play in Performative Frames. PhD dissertation, Malmö University.

Hobye, Mads, Nicolas Padfield, and Jonas Löwgren. 2013. Designing Social Play through Interpersonal Touch: An Annotated Portfolio. Presented at Nordic Design Research Conference, Copenhagen and Malmö.

Koskinen, Ilpo, John Zimmerman, Thomas Binder, Johan Redström, and Stephan Wensveen. 2011. Design Research through Practice: From the Lab, Field, and Showroom. Morgan Kaufmann.

Kyffin, Steven, Loe Feijs, and Tom Djajadiningrat. 2005. Exploring Expression of Form, Action and Interaction. Home-oriented Informatics and Telematics 178: 171-192.

Petersen, Marianne Graves, Ole Sejer Iversen, Peter Gall Krogh, and Martin Ludvigsen. 2004. Aesthetic Interaction: A Pragmatist's Aesthetics of Interactive Systems. In Proceedings of the Fifth Conference on Designing Interactive Systems: Processes, Practices, Methods, and Techniques (doi:10.1145/1013115.1013153).

Schön, Donald A. 1987. Educating the Reflective Practitioner. Jossey-Bass.

Shusterman, Richard. 2008. Body Consciousness: A Philosophy of Mindfulness and Somaesthetics. Cambridge University Press.

Vallgårda, Anna, and Tomas Sokoler. 2010. A Material Strategy: Exploring the Material Properties of Computers. International Journal of Design 4 (3): 1-14. 